\title{
A atuação da Companhia de Desenvolvimento da Área Metropolitana (CODEM): transformações, permanências e descontinuidades no planejamento urbano em Belém ${ }^{1}$
}

The performance of the Development Company of the Metropolitan Area (CODEM): transformations, permanencies and discontinuance in the urban planning in Belém

Tiago Veloso dos Santos[a] (1)

[a] Instituto Federal de Educação, Ciência e Tecnologia do Pará (IFPA), Belém, PA, Brasil

Como citar: Santos, T. V. (2020). A atuação da Companhia de Desenvolvimento da Área Metropolitana (CODEM): transformações, permanências e descontinuidades no planejamento urbano em Belém. urbe. Revista Brasileira de Gestão Urbana, 12, e20190141. https://doi.org/10.1590/2175-3369.012.e20190141

\section{Resumo}

A década de 1990 foi marcada por uma série de transformações no planejamento urbano em Belém. A Companhia de Desenvolvimento da Área Metropolitana (CODEM), sua principal instituição, passou a desempenhar um papel reativo, consequência da crise do planejamento urbano, mas também resultado das transformações políticas e institucionais. Apesar das mudanças, não se verificou o ocaso do planejamento tradicional, mas evidenciou-se um cenário ambíguo, caracterizado ora por mudanças com perfil reformista, ora pela hegemonia de perspectivas setoriais e fragmentadas de gestão. Nesse sentido, parte-se da hipótese de que a desestruturação das instituições do planejamento urbano não quer dizer, necessariamente, a completa ausência de processos de planejamento e gestão. O esgotamento dessas instituições está relacionado a um contexto de flexibilidade da administração, o que significa retirar o poder de decisão das velhas estruturas. Na Região Metropolitana de Belém, referência de análise, a CODEM acompanhou a realidade local e as transformações macroestruturais das políticas urbanas em nível nacional. 0 percurso metodológico desta pesquisa seguiu os procedimentos de: i) levantamento bibliográfico de caráter teórico e empírico; ii) levantamento e coleta documental acerca do papel da instituição na execução da política urbana em diferentes períodos; iii) entrevista semiestruturada com agentes relevantes da atuação da Companhia.

Palavras-chave: Planejamento urbano. Belém. CODEM.

\section{Abstract}

The 1990's marks a period of transformations in urban planning in Belém. The Development company of the Metropolitan Area (CODEM), the main institution, starts to play a reactive role, consequence of the urban planning crises, but also the result of the political and institutional transformations. Despite the

\footnotetext{
${ }^{1}$ Artigo produzido a partir do projeto de pesquisa “Trajetórias do Planejamento Urbano na Região Metropolitana de Belém (1973-2015)”, que contou com apoio institucional e financeiro do Instituto Federal de Educação, Ciência e Tecnologia do Pará (IFPA), por meio do Programa de Bolsas de Iniciação Científica, Tecnológica e Inovação (PIBICTI), no período 2015-2016. Este texto não poderia ter sido redigido sem o diálogo promovido no âmbito do Grupo de Estudos e Pesquisas sobre Ordenamento Territorial e Urbanodiversidade na Amazônia (GeoURBAM) do Núcleo de Altos Estudos Amazônicos da Universidade Federal do Pará, coordenado pelo professor doutor Saint-Clair C. da Trindade Júnior.
}

TVS é doutor em Desenvolvimento Socioambiental, docente, e-mail: tiago.veloso@ifpa.edu.br 
changes, there is no traditional planning, but there is an ambiguous scenario, which is characterized sometimes by reformist profile changes, other times the hegemony of sectoral and fragmented management perspectives. In this sense, one starts from the hypothesis that the destructuring of the institutions of urban planning does not mean, necessarily, the complete absence of planning and management processes. The exhaustion of these institutions is related to a context of flexibility of the administration, which means withdrawing the decision-making power of the old structures. In the Metropolitan Region of Belém, reference of analysis, CODEM has followed the local reality and macro-structural national policies. The methodological course of this research followed the procedures of: i) bibliographical survey of theoretical and empirical character; ii) survey and collection of documents about the role of urban policy implementation in different periods; iii) semi-structured interview with relevant agents of the Company's activities.

Keywords: Urban planning. Belém. CODEM.

\section{Introdução}

A década de 1990 foi marcada por uma série de transformações no planejamento urbano em Belém. A Companhia de Desenvolvimento da Área Metropolitana (CODEM), referência na estrutura de planejamento desde a década de 1970, tinha um papel executivo em âmbito municipal, obedecendo às políticas estabelecidas em outras esferas da tomada de decisão, como a esfera federal, que contava com órgãos como o Serviço Federal de Habitação e Urbanismo (SERFHAU), a Empresa Brasileira de Transportes Urbanos (EBTU) e o Banco Nacional de Habitação (BNH), e a esfera estadual, com o governo do Estado do Pará, por meio da Secretaria de Estado de Planejamento e Coordenação Geral (SEPLAN). Esse papel executivo constituído na década de 1970 foi consolidado e mantido até meados dos anos 1980.

A partir dos anos 1990, esse papel passou por modificações, derivadas do contexto político nacional, com a promulgação da Constituição, em 1988, que dedicou dois capítulos à política urbana e proporcionou o ambiente normativo de mudanças das estruturas e instituições de planejamento do regime civil-militar, o que provocou a alteração na atuação da CODEM.

Houve, ao mesmo tempo, mutações relacionadas às dinâmicas da globalização e mudanças no papel do Estado pelas quais passou a sociedade brasileira. Dentro da perspectiva do que Lefebvre (2001) chama de ordem próxima e ordem distante ${ }^{2}$ para a realidade urbana, tais mudanças são componentes do fenômeno analisado, ou seja, uma articulação entre fenômenos no espaço urbano local e o contexto em escala mais ampla do próprio fenômeno, no qual a compreensão das relações que o objeto estabelece com o ambiente imediato é elemento incontornável (Santos, 2015).

Tais mudanças, em tese, possibilitariam uma atuação de natureza mais abrangente da CODEM em relação ao passado imediato. Em vez de obedecer a políticas preestabelecidas em escalas hierárquicas superiores, a Companhia poderia estabelecer políticas mais próximas e com maior permeabilidade à realidade com a qual lidava no cotidiano. De fato, um movimento foi dado nessa direção quando a Companhia liderou a elaboração do Plano Diretor de Belém no início dos anos 1990, o qual, naquele momento, foi um articulador de aspirações por uma nova política urbana.

Apesar disso, essa tentativa de liderar um novo momento das políticas urbanas municipais com caráter reformista foi perdendo fôlego, fosse pelas mudanças políticas sentidas pelo município, fosse pela desidratação institucional e financeira, reflexo da retirada de poder das estruturas do passado, do qual a CODEM, apesar das mudanças, não deixava de ser expressão.

\footnotetext{
2 "A cidade é uma mediação entre as mediações. Contendo a ordem próxima, ela a mantém; sustenta relações de produção e de propriedade; é o local de sua reprodução. Contida na ordem distante ela se sustenta; encarna-a; projeta-a sobre um terreno e sobre o plano da vida imediata" (Lefebvre, 2001, p. 46).
} 
A CODEM passou então a desempenhar um papel reativo de atuação, consequência da crise do planejamento urbano, enquanto teoria e prática, mas também resultado das transformações nas estruturas políticas, econômicas e institucionais do município. Nesse cenário, evidenciou-se um cenário ambíguo de transformações e permanências, caracterizado pela gradual mudança do temário do planejamento por perspectivas setoriais fragmentadas de gestão do espaço urbano que, constituídos na primeira década de 2000, tornaram-se hegemônicas na atuação da Companhia até os dias mais recentes.

Vista dessa forma, a manutenção de uma instituição em um ambiente no qual não foi gerada significa a tentativa da estabilidade no sistema de ação política, tendo como base a manutenção dos processos de burocratização. A manutenção assim proporcionada viabiliza a estrutura burocrática, mas sem perspectiva de protagonismo na condução das políticas.

Nesse sentido, parte-se da hipótese de que a desestruturação das instituições do planejamento urbano não quer dizer, necessariamente, a ausência de processos de planejamento e gestão. 0 esgotamento dessas instituições está relacionado a um contexto de maior flexibilidade da administração, o que significa retirar o poder de decisão das velhas estruturas, especialmente aquelas comandadas pela tecnoburocracia estatal.

A dinâmica de crise permanente das práticas e políticas de planejamento urbano parece ser uma das causas dessa mudança na "ordem de importância" das instituições de planejamento urbano. No passado, imbuídas de ideais de construção de novas sociedades a partir da projeção de novas cidades, tais instituições estavam imersas na produção de planos que pudessem dar conta da mudança. Dada a dimensão da crise e o cotidiano de incertezas de um mundo que deixa de ser "sólido3", o papel desses órgãos foi redesenhado para cumprir funções e atividades em uma escala muito menor de abrangência. É esse processo que perdurou nas últimas duas décadas e que pôde ser visualizado em Belém a partir da atuação da CODEM que será tratado aqui.

\section{O ponto de partida: a institucionalização e o ensaio de modernização}

A Companhia de Administração e Desenvolvimento da Área Metropolitana (CODEM), responsável pelas respostas às demandas de caráter metropolitano, foi criada no âmbito da Prefeitura Municipal de Belém, com objetivos de ordenamento sociopolítico e econômico da área metropolitana, por meio da elaboração de planos e projetos pautados no relacionamento entre os poderes estadual e federal. Expressão de uma preocupação iniciada na década de 1960:

Em meados da década de 60, em função de preocupação quanto a um possível caráter metropolitano da problemática urbana de Belém e sua região de entorno, foi realizada pelo IBGE (2013) [Instituto Brasileiro de Geografia e Estatística], uma primeira delimitação espacial desta região. Esta delimitação estabeleceu como integrante da área Metropolitana de Belém (AMBEL), os municípios de Belém, Ananindeua e Benevides (CODEM, 1978, p. 20).

Nesse contexto, a CODEM aparece como expressão institucional do olhar do município voltado ao planejamento metropolitano. Criada pela Lei Municipal no 6.795 de 1970 e alterada pela Lei no 6.861 de 1971, regida pela Lei das Sociedades Anônimas e por estatuto social próprio, a CODEM é uma sociedade de economia mista, cujo maior acionista é a Prefeitura de Belém.

De fato, o ponto de partida da atuação da CODEM como órgão de planejamento foi a institucionalização da Região Metropolitana de Belém (RMB). Foi componente de uma política de

\footnotetext{
${ }^{3}$ Referência a um mundo "sólido" (Bauman, 2001) acerca das mudanças no final do século XX. Tais mudanças desconfiguram os ideais do projeto moderno associado a discursos (...) ligados à unidade social, à segurança e aos espaços territoriais bem definidos. Tais valores são contraditados por outros, impostos pela modernidade: insegurança, contradição, ambiguidade, incertezas e ausência de referenciais, configurando uma "modernidade líquida" que quebra a natureza do urbanismo enquanto projeto urbano. 0 declínio da doutrina urbanística aparece como expressão dessas mudanças, considerando que o urbanismo esteve fundamentado em ideais progressistas e em um tipo particular de coesão social que lhe dava estabilidade (Santos, 2015).
} 
desenvolvimento urbano em escala nacional, com a Lei Complementar no 14 de 1973, que estabeleceu as nove primeiras regiões metropolitanas do Brasil e enumerou os serviços de interesse metropolitano: planejamento do desenvolvimento econômico e social, saneamento básico (água, esgoto e limpeza pública), uso do solo, transportes e sistema viário, gás canalizado, aproveitamento de recursos hídricos e controle da poluição ambiental (Pacheco, 1995).

No momento em que foi efetivada a RMB, a CODEM foi imediatamente visualizada como a instituição adequada ao papel de coordenação das políticas metropolitanas:

somente em 1970, com a criação da CODEM, foi que se estabeleceu uma prática de planejamento sistematizado. Até então, a ação do planejamento urbano integrado, voltado à ordenação dos espaços e à gerência dos diferentes setores da economia, tinha se manifestado apenas por meio de trabalhos de caráter acadêmico (Pará, 1980, p. 20).

A forma como foi assumida essa institucionalização via administração federal marcou esse momento das políticas para as áreas metropolitanas no Brasil. Para Lopes (2006, p. 144):

O modelo de planejamento nesse período caracterizou-se por meio da iniciativa, da vinculação institucional, da sustentação política e financeira e do repertório de ações metropolitanas empreendidas pelo governo federal. 0 contraponto correspondente era a perda de poder e autonomia política e financeira dos municípios em geral e da periferia metropolitana em especial.

Criou-se uma superestrutura federal de apoio técnico e econômico ao desenvolvimento urbano e às regiões metropolitanas. Surgiram ou foram fortalecidas instituições como o Banco Nacional de Habitação (BNH), o Serviço Federal de Habitação e Urbanismo (SERFHAU) e a Comissão Nacional de Política Urbana e Regiões Metropolitanas (CNPU), além dos Fundos de Desenvolvimento Metropolitano.

Destacam-se então como características do período para o planejamento e a gestão metropolitana: a) o componente autoritário das intervenções, materializadas na centralização de decisões na esfera federal; b) o estabelecimento de uma estrutura para planejar, financiar e executar as ações metropolitanas; c) a disponibilidade de recursos para implementar projetos metropolitanos, especialmente em transportes.

A natureza empresarial da Companhia era expressão de um contexto relacionado à criação do SERFHAU, o qual introduzia um elemento novo nos sistemas de planejamento urbano - as empresas de engenharia consultiva. Segundo Santos (2015, p. 63, grifos nossos):

Na função de órgão de assistência técnica o SERFHAU ficou encarregado de elaborar normas, roteiros e padrões para a elaboração dos Planos Locais de Desenvolvimento Integrado, que junto ao Fundo de Financiamento de Planos de Desenvolvimento - FIPLAN, constituiriam um Sistema Nacional de Planejamento do Desenvolvimento, [...] formado por estruturas regionais, estaduais e municipais que desenvolveriam planos e estudos. Neste sistema, ficaria a cargo do SERFHAU a coordenação e supervisão geral dos planos, atribuindo a execução a órgãos especializados, públicos ou privados. Houve predominância das empresas privadas na execução, gerando uma dinâmica de terceirização dos planos a empresas de engenharia consultiva, marcada por uma separação entre a atividade técnica e a ação política da administração.

Para Ferreira (2007), tanto a institucionalização da assistência aos municípios como a criação de órgãos visando ao planejamento no interior das administrações municipais vinham sendo implementadas desde os anos 1950. No caso da CODEM, entre suas atribuições de origem estavam:

1. Administrar e explorar economicamente os bens e direitos da Prefeitura de Belém, que lhe forem conferidos com vistas à integração e adequação dessa atividade mercantil aos objetivos de estabelecimento e implementação do PLANO MUNICIPAL DE DESENVOLVIMENTO INTEGRADO (PMDI); 
2. Promover, junto com os órgãos competentes, o estabelecimento e implementação do PLANO METROPOLITANO DE DESENVOLVIMENTO INTEGRADO para a área da "GRANDE BELÉM";

3. Elaborar, direta ou indiretamente, estudos e projetos globais ou setoriais de interesse do desenvolvimento metropolitano (CODEM, 1970, p. 1).

Foi nesse período que se intensificaram as atividades de planejamento e gestão da RMB, visto que a CODEM era responsável pela elaboração dos planos de desenvolvimento da área metropolitana. Os planos da Grande Belém ${ }^{4}$ eram na modalidade compreensiva ${ }^{5}$ de planejamento e associados às práticas financiadas pelo SERFHAU.

Embora a orientação dos planos tornasse a dimensão metropolitana obrigatória para a solução de problemas, as competências da CODEM tinham vinculações relacionadas aos problemas da capital, e não ao seu espaço metropolitano. Isso gerou controvérsias dentro da instituição ${ }^{6}$, que acabou sendo resolvida com a CODEM tornando-se um braço operacional na estrutura do Sistema Estadual de Planejamento.

O contexto político centralizador favoreceu a operacionalização de um sistema de gestão em que instâncias, para além da escala municipal, tomavam as principais decisões na região metropolitana. Era a instância estadual - o governo do Estado do Pará - quem de fato planejava o espaço metropolitano a partir de uma perspectiva nem sempre relacionada às demandas sociais.

Esse processo, consolidado em 1975 com o Sistema Estadual de Planejamento, sob coordenação da Secretaria de Estado do Planejamento e Coordenação Geral (SEPLAN), passou a ter a função da gestão metropolitana, articulada politicamente aos dois conselhos que permitiam algum tipo de participação no processo decisório, o Conselho Consultivo (Consul) e o Conselho Deliberativo (Conbel). Para Pinheiro et al. (2013, p. 55):

[...] após a criação das RMs, o governo federal, implantou a Comissão Nacional de Regiões Metropolitanas e Políticas Públicas, para elaborar e gerenciar as políticas [...] metropolitanas de forma integrada. Por sua vez, o governo do estado do Pará criou, em 1975, o Sistema Estadual de Planejamento, anexado à Secretaria de Estado de Planejamento e Coordenação Geral (SEPLAN), tendo como competência criar políticas públicas de desenvolvimento local, municipal e metropolitano.

Com esse formato, a gestão da RMB passou a conviver com dois atores: de um lado, as ações da CODEM para o território municipal; do outro, o governo estadual viabilizava o Sistema Estadual de Planejamento, articulado a Brasília. Segundo Fernandes (2001):

Na sua primeira fase, no período 1973/1975, a gestão da RMB, embora não regulamentada na perspectiva supramunicipal, foi realizada pela CODEM - entidade vinculada à administração do Município de Belém. Com a institucionalização do Sistema Estadual de Planejamento - SEP, em 1976, a gestão metropolitana passou a integrar o elenco de competências da Secretaria de Estado do Planejamento e Coordenação Geral - SEPLAN, Órgão Central do Sistema, cuja estrutura abrigava um setor voltado a essa questão. (Fernandes, 2001, p. 23).

\footnotetext{
${ }^{4}$ Lamarão Corrêa (1989) denomina “Grande Belém" o espaço metropolitano de Belém nas décadas de 1970 e 1980, naquele momento constituída pelos municípios de Belém e Ananindeua.

${ }^{5}$ Os planos compreensivos são uma modalidade de planejamento urbano que ultrapassa a lógica do planejamento físico-territorial. Este primava pela preocupação com a modernização da infraestrutura da cidade e tinha forte vinculação com os arquitetos e engenheiros que aplicavam essa perspectiva. Aquele, por sua vez, além da preocupação com a infraestrutura urbana, compreendia as dinâmicas socioeconômicas na cidade. Além disso, trazia o envolvimento de equipes multidisciplinares na elaboração de planos: arquitetos, engenheiros, sociólogos, administradores, advogados, geógrafos e economistas (Lamarão Corrêa, 1989).

6 "Grande parte dos objetivos fixados na legislação municipal que criou as companhias e nos dispositivos estatutários antecederam a criação das regiões metropolitanas por legislação federal [...] Resultando que tais metas tornaram-se irrealizáveis porque, sendo a CODEM uma empresa municipal de Belém, não poderia estabelecer normas e diretrizes, por exemplo, para o município de Ananindeua". Destituída da condição de órgão executor decorrente da iniciativa, na distribuição de funções da gestão metropolitana de então, coube à CODEM o papel de braço operacional do Sistema Estadual de Planejamento (CODEM, 1992, p. 3).
} 
Para Deák (2004), o período que vai de meados da década de 1960 até o fim do "milagre econômico" em 1973 diz respeito à "era de ouro" do planejamento urbano no Brasil. A reflexão sobre esse período destaca a existência de uma política de desenvolvimento que definia linhas gerais para o território. Ainda assim, tal política refletia as dificuldades no atendimento à particularidade da condição amazônica, por exemplo, a proporção de população urbana e rural abaixo da média nacional para áreas metropolitanas.

Em 1980, Belém detinha 88,33\% de população urbana, enquanto Ananindeua, apenas 10,40\%. Embora em conjunto isso correspondesse, na época, a 83,2\% da população urbana, de fato, em aspecto qualitativo, há uma evidente discrepância na condição metropolitana quando comparadas a outras metrópoles nacionais. A atuação da CODEM, portanto, foi essencial para a mediação entre a política pensada em escala nacional, suas diretrizes gerais, o acesso às fontes de financiamento e o que era efetivamente executado na Região Metropolitana de Belém. Essa mediação obedeceu a imperativos de ordem ideológica, por exemplo, o uso da razão instrumental como elemento de operacionalização de mudanças desejadas para a Grande Belém.

\section{O apogeu da razão instrumental: a CODEM e os planos-representações da cidade}

Obedecendo ao imperativo de produção das diretrizes para o planejamento urbano, a CODEM, ao longo da década de 1970 e início dos anos 1980, coordenou a produção de planos de desenvolvimento urbano e metropolitano. Em que pese a eventual fragilidade do aparato estadual de planejamento e gestão, foram realizadas ações, destacando-se a elaboração dos planos compreensivos da Grande Belém (Lamarão Corrêa, 1989). A concepção e a elaboração desses planos foram influenciadas pela atuação do Serviço Federal de Habitação e Urbanismo:

Os planos promovidos pelo SERFHAU tinham, por campo de intervenção, os aspectos sociais, econômicos, físicos e institucionais - daí a denominação de planos integrados. Seu método era o de aproximações sucessivas: [...] um estudo preliminar, [seguido de] um plano de ação ou um plano de desenvolvimento local integrado. A etapa primeira era a identificação dos problemas e dos agentes do desenvolvimento local, as propostas para solução dos problemas locais mais urgentes. A etapa subsequente, após diagnóstico da etapa anterior, tinha por conteúdo as alternativas de intervenção, a solução para os principais problemas e pontos de estrangulamentos, os instrumentos legislativos, a demanda de recursos, os programas setoriais relevantes. A etapa final os planos setoriais ou mesmo anteprojetos, o organismo local de planejamento, o detalhamento dos instrumentos administrativos (Minter [Ministério do Interior] apud Moreira, 1989, p. 3).

Houve sintonia entre as propostas apresentadas pelo SERFHAU e a elaboração dos planos compreensivos desenvolvidos pela CODEM. Lamarão Corrêa (1989, p. 239) assim os descreve:

[...] se fundamentam em um diagnóstico abrangente da realidade intraurbana e são equacionados a partir da formulação de uma imagem projetada da cidade, onde são estrategicamente posicionados os elementos fundamentais do espaço urbano futuro. Dentre eles, a distribuição espacial, de densidade, de rendas per capita, ou familiares e de emprego. Ainda contam para isso a estrutura viária básica e a localização de equipamentos urbanos de dimensão significativa ou de grande importância funcional.

Três foram os planos elaborados para a "Grande Belém": o Plano de Desenvolvimento da Grande Belém (PDGB), o Plano de Estruturação Metropolitana (PEM) e o Plano de Desenvolvimento Metropolitano (PDM), conforme o Quadro 1. 
Quadro 1 - Planos compreensivos da Grande Belém

\begin{tabular}{|c|c|c|c|}
\hline PLANOS & $\begin{array}{c}\text { PLANO DE } \\
\text { DESENVOLVIMENTO DA } \\
\text { GRANDE BELÉM (PDGB) }\end{array}$ & $\begin{array}{l}\text { PLANO DE DIRETRIZES } \\
\text { METROPOLITANAS (PDM) }\end{array}$ & $\begin{array}{l}\text { PLANO DE ESTRUTURAÇÃO } \\
\text { METROPOLITANA (PEM) }\end{array}$ \\
\hline PERÍODO & $1974-1976$ & 1976-1977 & $1979-1981$ \\
\hline BASE TEÓRICA & Funcionalista. & $\begin{array}{l}\text { Funcionalista, mantém } \\
\text { estrita vinculação com o } \\
\text { PDGB. }\end{array}$ & $\begin{array}{l}\text { Eclética, apresentou-se } \\
\text { como "histórico-estrutural". }\end{array}$ \\
\hline $\begin{array}{c}\text { ESTRUTURA } \\
\text { METODOLÓGICA }\end{array}$ & $\begin{array}{c}\text { Roteirização adotada pelo } \\
\text { SERFHAU para os Planos de } \\
\text { Desenvolvimento } \\
\text { Integrados. }\end{array}$ & $\begin{array}{c}\text { Composto de } \\
\text { diagnósticos, diretrizes } \\
\text { e projetos/programas. } \\
\text { Evitou as superposições do } \\
\text { PDGB, mas apresentou } \\
\text { setorização semelhante. }\end{array}$ & $\begin{array}{l}\text { Ełapas de elaboração: } \\
\text { levantamento de } \\
\text { informações, análise e } \\
\text { diagnóstico, projeção de } \\
\text { variáveis, formulação de } \\
\text { futuros, definição de } \\
\text { estrutura metropolitana, } \\
\text { simulação de usos, } \\
\text { programas e projetos. }\end{array}$ \\
\hline INSTRUMENTAÇÃO & $\begin{array}{l}\text { Limitou-se a trabalhar com } \\
\text { mecanismos de } \\
\text { zoneamento, código de } \\
\text { edificações e posturas. }\end{array}$ & $\begin{array}{c}\text { Restringiu-se à listagem de } \\
\text { programas e projetos, a } \\
\text { maioria referentes a } \\
\text { estudos, pesquisas, } \\
\text { formulações de planos, } \\
\text { avaliações e } \\
\text { complementação do } \\
\text { PDGB. }\end{array}$ & $\begin{array}{c}\text { Apresentou o fundo de } \\
\text { terras para que o poder } \\
\text { público pudesse intervir de } \\
\text { forma mais efetiva na } \\
\text { produção do espaço } \\
\text { urbano. }\end{array}$ \\
\hline CONCLUSÕES & $\begin{array}{c}\text { O contexto autoritário e a } \\
\text { base teórica inconsistente } \\
\text { repercutiram em } \\
\text { metodologia } \\
\text { problemática, com } \\
\text { setorização analítica e } \\
\text { projetiva, que redundou } \\
\text { em projeções superficiais e } \\
\text { distorcidas. }\end{array}$ & $\begin{array}{c}\text { Estruturado } \\
\text { metodologicamente e } \\
\text { com pequena efetividade, } \\
\text { padeceu dos problemas } \\
\text { do PDGB por ter sido } \\
\text { elaborado quase no } \\
\text { mesmo contexto } \\
\text { sociopolítico e ter base nas } \\
\text { formulações do PDGB. }\end{array}$ & $\begin{array}{l}\text { Formulado na transição, } \\
\text { avançou no entendimento } \\
\text { do planejamento urbano, } \\
\text { o que repercutiu no } \\
\text { tratamento dialético das } \\
\text { análises. As inovações } \\
\text { resultaram, entretanto, em } \\
\text { baixa efetividade, } \\
\text { atribuída ao contexto de } \\
\text { transição e às carências } \\
\text { das inovações. }\end{array}$ \\
\hline
\end{tabular}

Fonte: Lamarão Corrêa (1989); Veloso dos Santos (2010). Organização: Tiago Veloso dos Santos.

Os planos foram dotados de estrutura metodológica e entendimento teórico sobre a urbanização em Belém. Em termos de novas possibilidades de configurações do espaço metropolitano, viabilizaram modelos de desconcentração de serviços, fato que ficou exposto no PEM com a tentativa de uma "descentralização concentrada". A ideia de criar subcentros no conjunto do espaço metropolitano, de maneira a descompactar a Primeira Légua Patrimonial, conforme a Figura 1. Na prática, apenas os novos assentamentos residenciais foram alocados para a área de expansão, o mesmo não acontecendo com empregos, comércio, serviços e estrutura viária (Trindade, 1998). 


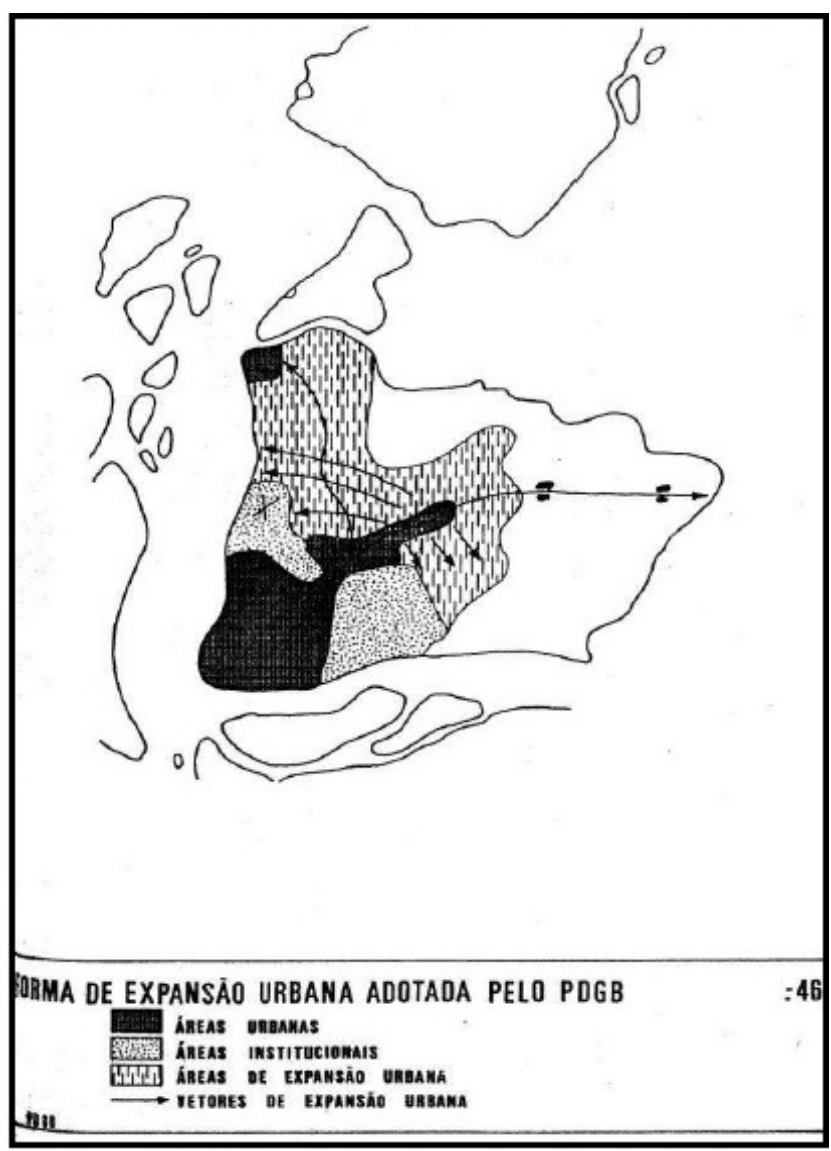

Figura 1 - Previsão de expansão urbana adotada pelo PDGB. Fonte: CODEM (1975).

Com o fracasso pela baixa efetividade em minimizar as desigualdades socioeconômicas, logo surgiram os diagnósticos para compreender suas causas, que podem ser agrupadas em duas vertentes. O primeiro grupo colocava como causas a falência do planejamento centralizado, a falta de participação dos agentes envolvidos e a tomada do planejamento pela tecnoburocracia privada e/ou estatal. No segundo grupo, destacavam-se elementos externos, como a crise fiscal, o que dificultava o financiamento de grandes sistemas de planejamento.

Tal diagnóstico alcançou a atuação da CODEM como instituição responsável pela viabilização das políticas de planejamento. Apesar de propor orientações para a expansão da Belém metropolitana, isso não foi suficiente para mitigar os problemas de desigualdade na cidade, os quais, ao contrário do esperado, foram intensificados. Tal contexto mobilizou a compreensão pela necessidade de modelos alternativos de planejamento e gestão do espaço urbano.

\section{O declínio: a crítica à centralização e à desestruturação do planejamento}

As críticas ao planejamento tecnocrático, elaboradas por movimentos sociais, como o Movimento Nacional pela Reforma Urbana, e os rumos da redemocratização do país, na década de 1980, deram origem a proposições de formas alternativas de planejamento e gestão urbana, das quais o novo Plano Diretor incluído na Constituição de 1988 foi a maior expressão normativa.

Naquele momento, o regime militar apresentava sinais evidentes de desgaste, que resultaram em um processo de abertura democrática. Diante de um cenário de fragilização política e recessão econômica, a política urbana sofreu constrangimentos mediante a escassez de financiamento.

Foi nesse momento que a face do planejamento urbano mudou de escala. Se, na década de 1970, havia uma preocupação em políticas no âmbito metropolitano, no período posterior, a partir de 1988, 
foi a escala municipal que passou a ser privilegiada nas políticas de planejamento urbano. A própria Constituição faz referência à escala municipal: "Art. 182. A política de desenvolvimento urbano, executada pelo poder público municipal, conforme diretrizes gerais fixadas em lei, tem por objetivo ordenar o pleno desenvolvimento das funções sociais da cidade e garantir o bem-estar de seus habitantes" (Brasil, 1998, p. 56).

Esse movimento de transformação institucional deu legitimidade à desestruturação da maior parte das instituições que constituíam os sistemas de planejamento urbano. Instituições como o Serviço Federal de Habitação e Urbanismo, a Empresa Brasileira de Transportes Urbanos e o Banco Nacional de Habitação foram quase que sumariamente eliminados da estrutura do Estado ${ }^{7}$. As secretarias estaduais, quando não extintas, foram alocadas em funções de natureza distintas, ligadas ao planejamento orçamentário, e perderam espaço na configuração política e na distribuição de recursos. Ficou claro que o município assumiu responsabilidade primordial na elaboração e execução das políticas de desenvolvimento, planejamento e gestão urbana, especialmente a partir do estabelecimento do instrumento denominado Plano Diretor.

Foi esse espaço de atuação em âmbito municipal que permitiu à CODEM a legitimidade da permanência na estrutura de planejamento. No início dos anos 1990, esse contexto de desestruturação institucional e necessidade de maior atuação municipal em torno do planejamento urbano em âmbito municipal garantiu à Companhia um momento de atuação primaz.

\section{Ensaios de transformação: o revigoramento reformista dos anos 1990}

A conjuntura nacional propiciou um fortalecimento do movimento em torno da "municipalização" das políticas de planejamento e gestão urbana. Foi esse contexto que possibilitou a manutenção da CODEM como instituição de planejamento. Se, por um lado, a Companhia representava uma orientação de política metropolitana que estava em vias de ser superada, por outro lado, a experiência e a expertise de seu corpo técnico davam à instituição legitimidade para participar do novo contexto. A ausência de outras instâncias de planejamento na Prefeitura de Belém dava uma vantagem à CODEM, que foi aproveitada quando surgiu um elemento mobilizador do planejamento municipal: a construção do Plano Diretor da cidade.

O Plano Diretor de Belém teve seu início de elaboração no ano de 1991, com os estudos de referência para a posterior promulgação, que ocorreu em 1993. A CODEM conduziu o processo de construção dos estudos do Plano, considerando as várias fases de desenvolvimento até a elaboração final na forma de lei.

A análise do primeiro Plano Diretor pós-Constituição, portanto em período democrático, constata que era um documento orientado pelo ideário da reforma urbana e constituía exemplo da influência desse ideário na construção dos Planos Diretores no Brasil, bem como de uma perspectiva de desenvolvimento que considerava os elementos idealizados como necessários a uma nova prática de produção das cidades.

Souza (2010) classifica esse tipo de prática de planejamento e gestão urbanos sob uma perspectiva social-reformista, posto que visa, por meio de mecanismos de controle e regulação do uso do solo, racionalizar o uso da terra urbana para além do valor de mercado. Trata-se de dar função social da cidade e da propriedade na produção do espaço urbano. 0 primeiro plano diretor de Belém assume várias dessas características, posto que o período de elaboração foi propício à influência do ideário reformista que, em virtude das demandas que resultaram na Constituição de 1988, ganhou força no imaginário e na prática do planejamento e da gestão urbana.

0 elemento central, do ponto de vista da resolução dos problemas urbano-metropolitanos, é o cumprimento da função social da cidade para promoção da justiça social no espaço urbano,

\footnotetext{
7 O SERFHAU foi extinto em 1975, reflexo dos efeitos sobre o orçamento do primeiro "choque do petróleo", em 1974, e da mudança de orientação na administração Geisel. O BNH foi extinto em 1986, por meio do Decreto-Lei no 2.291, sendo incorporado à Caixa Econômica Federal, que o sucedeu em seus direitos e obrigações, sobretudo a gestão do Fundo de Garantia do Tempo de Serviço (Ferreira, 2007).
} 
conforme se pode verificar pelos princípios gerais e dos instrumentos urbanísticos usados para garantir o cumprimento desses princípios (Belém, 1991, p. 1).

Fica clara a associação das ideias do primeiro Plano Diretor de Belém com as teses defendidas pelo Movimento Nacional da Reforma Urbana: maior regulação do uso do solo, distribuição mais equitativa dos recursos no espaço urbano e participação social na construção das políticas públicas. Além disso, o Plano Diretor avançou para além das demandas do ideário da reforma urbana, no sentido da necessidade de trabalhar os problemas da cidade como uma perspectiva metropolitana.

Entretanto, apesar da associação com o ideário da reforma urbana, o Plano Diretor de Belém era tímido na questão da abertura à participação popular nas políticas de planejamento e gestão urbana. Os poucos momentos de participação ficaram restritos à elaboração do relatório de diagnósticos e, mesmo assim, foram prejudicados em virtude do pouco tempo dedicado a esse aspecto.

Ao que parece, a herança institucional da CODEM representou a continuidade de duas características presentes na produção tecnoburocrática do período antecedente. Em primeiro, a capacidade de elaboração de diagnósticos abrangentes da realidade, com uma relativa presença de elementos pouco destacados anteriormente, como ideias e conceitos ligados à necessidade de maior justiça espacial na produção da cidade. Em segundo, dificuldade de materializar formas de participação social, o que, no caso específico, apesar da boa vontade existente, acabou redundando em pouco mais do que uma certa tolerância para com formas simples de pseudoparticipação da população no desenvolvimento de políticas de planejamento e gestão do espaço urbano.

\section{Conflitos e mudanças: a década de 1990 e a modificação de perfil político-administrativo}

A década de 1990, especialmente a partir de 1996 com a chegada ao governo de Belém de uma gestão liderada por um partido de esquerda, alterou a disposição da CODEM no planejamento municipal. Dois elementos explicam essa mudança: a organização, por parte da nova administração, de um tipo de planejamento com pressupostos distintos dos que haviam constituído a CODEM originalmente; e a própria natureza empresarial da Companhia, vista com desconfiança pela nova gestão.

A eleição ao governo municipal do Partido dos Trabalhadores ${ }^{8}$ significou a chegada de um grupo político crítico às modalidades de planejamento e gestão executadas em escala nacional desde os anos 1980, e que, como visto, a CODEM era a expressão institucional local. Os documentos que orientaram a nova gestão ressaltavam a necessidade de conduzir essas práticas de forma oposta ao que havia sido desenhado até então:

O Governo do Povo (sic) rompe com a visão tecnocrática do mero estabelecimento de metas e formulação de planos normativos. 0 planejamento no Governo do Povo (sic) é um movimento vivo que se realiza no orçamento participativo, nas conferências setoriais, etc. (Rodrigues \& Novaes, 2002, p. 25).

No interior da nova administração, conduzia-se a construção de políticas de planejamento que reforçassem o distanciamento em relação ao passado. As novas estratégias deveriam estar ancoradas em maior participação de atores sociais anteriormente alijados das demandas:

Tal estratégia assume a perspectiva de afirmação de uma forma de governar em que o planejamento significa e pressupõe participação política, mobilização social e reconhecimento pelo governo das particularidades de uma cidade marcada pela exclusão e pelo abafamento do seu potencial transformador (Rodrigues \& Novaes, 2002, p. 25).

\footnotetext{
${ }^{8}$ Nas eleições de 1996, foi eleito Edmilson Rodrigues, da "Frente Belém Popular", formada majoritariamente por partidos da esquerda do espectro político: PT - Partido dos Trabalhadores; PSTU - Partido Socialista dos Trabalhadores Unificado; PCB - Partido Comunista Brasileiro; PPS - Partido Popular Socialista; PSB - Partido Socialista Brasileiro; PV - Partido Verde; PCdoB - Partido Comunista do Brasil. A coligação foi reeleita nas eleições de 2000, permanecendo oito anos no Executivo Municipal (1997-2005).
} 
No âmbito da gestão, isso significava explorar a natureza empresarial da CODEM para retirar a centralidade das políticas de planejamento e gestão da Companhia. Administrativamente, isso foi possibilitado com o fortalecimento de uma instância relativamente recente no organograma da Prefeitura, a Secretaria Municipal de Coordenação Geral do Planejamento e Gestão ${ }^{9}$ (SEGEP), órgão do Sistema Municipal de Planejamento e Gestão, que passou a conduzir a política de desenvolvimento. Essa reorganização administrativa proporcionava uma orientação distinta da existente na história local de planejamento municipal, possibilitando uma narrativa que associava a administração a um novo momento de condução das políticas:

[...] o planejamento do governo orientou-se para a formulação de um modelo político-institucional que proporcionasse incorporação das demandas da sociedade civil pelo corpo funcional, mas sem perder eficiência técnica e coerência programática. A questão era criar condições para identificar o corpo social com as instituições municipais, após décadas de distanciamento entre poder público e grande parte da cidade (Rodrigues \& Novaes, 2002, p. 30).

Com essa perspectiva, o executivo e sua assessoria passaram a ter papel central no planejamento:

O conjunto de coordenadores de Marcas, as secretarias de Planejamento (SEGEP) e de Finanças (SEFIN), a Coordenadoria de Relações com a Comunidade (CRC), a Coordenadoria de Comunicação Social (COMUS), o Gabinete do Vice-Prefeito e o Gabinete do Prefeito compõem o denominado Comitê do Plano, que sob a coordenação do Prefeito é a instância máxima, cuja função é coordenar a política do plano de ação e, acima de tudo, assegurar a sua governabilidade (Rodrigues \& Novaes, 2002, p. 35).

A CODEM foi extraoficialmente retirada da condução do planejamento e gestão, conforme o desenho institucional da administração. Entretanto, isso não significou que a Companhia ficou completamente sem função na política urbana.

Ela foi orientada interna e externamente a ser cada vez mais um órgão de "competência técnica", associando a expertise de seu corpo de servidores ao momento de retirada de sua centralidade na tomada de decisão em nível político. Segundo a própria administração:

Nessa perspectiva, o Governo do Povo (sic) não só desenhou um novo modelo de gestão e planejamento ágil, flexível e participativo, como também investiu maciçamente no provimento de uma infraestrutura de informações, hoje dentre as mais avançadas do País. Para isso, foi realizado um levantamento cadastral e aerofotogramétrico da cidade, que se inscreve entre os mais completos do Brasil. Com fins múltiplos, o Cadastro Técnico Multifinalitário, realizado pela CODEM, é um recurso para o planejamento a partir da consolidação de um sistema de informações que efetivamente aprofundará a democratização e o controle dos serviços públicos (Rodrigues \& Novaes, 2002, p. 28).

Isso dava também um certo respaldo político à administração, que não poderia ser acusada de ter viés ideológico, mas apenas de reorganizar administrativamente o corpo governamental segundo suas prioridades e visões tecnopolíticas. A mudança da orientação político-administrativa fez com que cada vez mais coubesse à CODEM, pela sua reconhecida capacidade técnica, ações consideradas operacionais, tais como a realização do cadastro multifinalitário ${ }^{10}$. Houve, portanto, uma nítida reorganização da estrutura do planejamento municipal, que se acentuou com o tempo e a consolidação da própria gestão, e que teve como culminância desse processo a retirada da CODEM do papel que lhe cabia originalmente.

\footnotetext{
${ }^{9}$ A SEGEP foi criada pela Lei Municipal no 7.341/86, no contexto de redemocratização e eleição de executivos municipais, o que não acontecia desde a década de 1960. Seu regimento interno aprovado pelo Decreto Municipal no 26.524 no início dos anos 1990 reforçava seu papel na condução do planejamento municipal, em contraponto à CODEM.

10 O Cadastro Técnico Multifinalitário (CTM) é um instrumento viabilizador das ações de política urbana, posto que, "sem cadastros e plantas de valores atualizados, não apenas a arrecadação do IPTU (Imposto Predial e Territorial Único, 'normal' e progressivo no tempo) é comprometida, mas a aplicação de vários instrumentos também pode ser prejudicada, comprometendo objetivos mais ambiciosos em matéria de um planejamento e uma gestão eficientes e progressistas" (Souza, 2010, p. 306)
} 


\section{Permanências fúteis: o esvaziamento do planejamento e o o caso institucional}

O início dos anos 2000 marcou a consolidação do esvaziamento da CODEM enquanto instituição de política urbana. Anteriormente braço executivo do sistema de planejamento federal e estadual com atuação municipal, teve seu papel alterado, posto que o sistema de planejamento foi desconstruído. As mudanças ao longo da gestão municipal entre 1997 e 2005 acabaram por consolidar a atuação da CODEM, mesmo após o término da gestão ${ }^{11}$.

Um momento representativo dessa perda de influência ocorreu no processo de revisão do Plano Diretor de Belém, posto que, conforme previsão legal do Estatuto da Cidade ${ }^{12}$, o Plano Diretor Municipal deveria ser revisto, pelo menos, a cada dez anos.

Em 2007, 15 anos após a promulgação do primeiro Plano Diretor Municipal, a Prefeitura iniciou o processo de revisão conforme previsão legal, conduzido agora pela Secretaria Municipal de Coordenação Geral do Planejamento e Gestão (SEGEP), responsável pela análise e compatibilização das propostas orçamentárias setoriais e pela alocação de recursos orçamentários e extraorçamentários nos programas municipais.

A SEGEP atuava de acordo com o Núcleo Gestor do Plano Diretor ${ }^{13}$, formado por representantes da sociedade civil e do governo, para atender às exigências do Estatuto da Cidade. Nesse sentido, a CODEM fez parte do núcleo gestor, mas longe de conduzir o processo de revisão, conforme ocorreu na década de 1990. Dessa forma, percebe-se que, embora ainda fizesse parte das políticas de planejamento e gestão, a CODEM passou a ter um papel apenas complementar às diretrizes, pois estas estavam em outros níveis e esferas de atuação. A Companhia, de certa forma, manteve-se como uma autarquia da Prefeitura de Belém, mas com atribuições menores, como explicitado por um de seus servidores:

A CODEM não tem competência para propor algum tipo de planejamento metropolitano, pois desde a Constituição de 1988 cabe ao governo do Estado legislar sobre essas áreas. A CODEM até pode ser responsável por algum tipo de articulação entre Estado e prefeitura nas áreas de interesse comum metropolitano, mas agora houve uma volta ao âmbito municipal (Entrevista com funcionário(a) da Diretoria de Desenvolvimento Urbano da CODEM, realizada em março de 2014).

De forma geral, a permanência da Companhia foi um pálido reflexo de sua atuação entre as décadas de 1970 e 1980. Dada a mudança de sua atuação, cada vez mais distante dos núcleos de decisão, da condução e da execução da política urbana em nível municipal, foi se especializando em questões técnico-administrativas, como a produção de produtos, documentos e relatórios que viabilizassem programas governamentais ou iniciativa em parceria com o setor privado, e cada vez mais atuando como uma espécie de órgão administrativo para questões fundiárias em termos de regulação do uso do solo urbano em Belém ${ }^{14}$. Isso passou a ser refletido nos documentos que norteiam a missão da CODEM em período recente:

[A Companhia visa a] ... contribuir na estrutura administrativa de Belém, por meio da regularização fundiária e ações integradas no planejamento urbano municipal, visando a melhorias na qualidade de vida da população. Por exercer atividade econômica mista, a Codem é uma empresa de amplas

\footnotetext{
${ }^{11}$ Nas eleições municipais de 2004, a Frente de Esquerda que governou durante oito anos foi derrotada por uma coligação de centro-direita, tendo à frente Duciomar Costa, na época do Partido Social Democrático (PSD), reeleito nas eleições de 2008, já pelo Partido Trabalhista Brasileiro (PTB).

${ }^{12}$ Estatuto da Cidade é o nome dado à Lei no 10.257, de 2001, que regulamentou os artigos 182 e 183 da Constituição e trata da política urbana nacional.

13 O Núcleo Gestor da Revisão do Plano Diretor contou com a seguinte composição: poder público (oito membros) - um representante do Executivo Federal, um representante do Executivo Estadual, quatro representantes do Executivo Municipal e dois representantes do Legislativo Municipal; sociedade organizada (12 membros) - três representantes de entidades da classe de trabalhadores, três representantes de entidades da classe patronal, três representantes de entidades comunitárias e eclesiásticas, e três representantes de entidades científicas, comunidades tecnológicas e conselhos regionais de classe (Belém, 2007).

${ }^{14}$ Entre os programas executados pela CODEM estão o "Chão Legal”, de regularização fundiária do município. Desenvolvido pela CODEM e pela Secretaria do Patrimônio da União (SPU), visa garantir o direito à moradia em ocupações irregulares (Belém, 2019).
} 
possibilidades e presta serviços também a terceiros, dentro do mercado imobiliário, um nicho em constante expansão em Belém (CODEM, 2005, p. 1).

Politicamente enfraquecida, financeiramente desidratada e administrativamente deslocada do centro da tomada de decisão do planejamento e da gestão urbana municipal, a Companhia não teve mais as funções às quais esteve vinculada em sua origem. Permaneceu enquanto mais um dos órgãos da Prefeitura Municipal de Belém, mas sem apresentar razões mais profundas que justificassem sua existência. Não deixa de ser uma expressão das mudanças na política urbana municipal que desestruturaram o sistema de planejamento.

\section{Conclusões}

Quando o gabinete da Presidência da República instituiu as Regiões Metropolitanas em 1973, tornou-se visível a importância que estas assumiriam na vida urbana nacional. Ficava claro que, ao se intensificar o processo de urbanização, as metrópoles teriam papel no modo de vida urbano que se impunha para a reprodução da sociedade em território nacional.

O reconhecimento institucional visava proporcionar políticas de planejamento do espaço metropolitano que dinamizassem a economia das metrópoles e mitigassem os efeitos "indesejados" da urbanização. A institucionalização promoveu os mecanismos de intervenção. Foram criadas instituições de políticas urbanas com ênfase no desenvolvimento. Houve mobilização de recursos para tais objetivos. Não obstante, a maior parte dos problemas urbanos se intensificou em virtude da estagnação econômica e do fim do modelo de planejamento e financiamento da política urbana.

Pode-se afirmar que o formato das políticas contribuiu para o agravamento dos problemas nas metrópoles. Centralizador, burocrático, autoritário, pouco afeito à participação e praticamente impermeável às várias realidades metropolitanas, a dinâmica planificadora primou pela burocratização da questão urbana.

O contexto da redemocratização permitiu um novo marco regulatório, via Constituição. A arquitetura institucional da política urbana a partir de 1988 teve como um de seus alicerces a rejeição ao arcabouço anterior, o que desmobilizou a construção de mecanismos abrangentes de políticas metropolitanas.

De forma geral, esses elementos da trajetória do planejamento urbano no Brasil são válidos para a Região Metropolitana de Belém e suas instituições de planejamento e gestão. A metrópole belenense, formada a partir da década de 1960, figura entre as primeiras nove regiões metropolitanas instituídas em 1973.

Esse período marcou a criação da Companhia de Desenvolvimento da Área Metropolitana, responsável pelos programas e projetos na RMB e pela coordenação dos planos compreensivos da Grande Belém, alinhados às políticas nacionais. A atuação operacional da CODEM foi fundamental na política urbana, para além da construção de planos, pois orientou as diretrizes de expansão metropolitana.

A partir do esgotamento do regime civil-militar, a face do planejamento urbano mudou de escala. Se, na década de 1970, havia preocupação com políticas de planejamento no âmbito metropolitano centralizadas, no período posterior foi a escala municipal que passou a ser privilegiada nas políticas urbanas. Isso pode ser exemplificado na retirada da CODEM das etapas de planejamento a partir de então, ainda que, em um primeiro momento, a Companhia tivesse se mobilizado internamente para alterar sua orientação programática.

Mas havia uma contradição nas formas de pensar o planejamento e a gestão que ficou exposta no período 1997 a 2005, contradição intensificada com a gestão do executivo municipal, refratária às práticas de planejamento e gestão mais comuns da Companhia, além da resistência à participação de uma instituição de natureza empresarial como responsável pelas políticas urbanas em Belém. 
O progressivo esvaziamento da CODEM do escopo das políticas de planejamento e gestão tomou uma direção que foi consolidada até os dias atuais.

De forma geral, compreende-se, a partir da atuação da CODEM, que a desestruturação das instituições ligadas ao planejamento urbano não quer dizer, necessariamente, a completa ausência de processos de planejamento e gestão. Mas o esgotamento dessas instituições está relacionado a um contexto de mudanças em direção a maior nível de flexibilidade da administração, o que significou, nesse caso, a retirada do poder de decisão das antigas estruturas, especialmente as comandadas pela tecnoburocracia estatal. Na Região Metropolitana de Belém, referência empírica de análise, a atuação da CODEM acompanhou, de forma particular à própria realidade local, as transformações macroestruturais das políticas de planejamento e gestão em nível nacional.

\section{Referências}

Bauman, Z. (2001). Modernidade líquida. Rio de Janeiro: Jorge Zahar.

Belém. (1991). Relatório de diagnósticos do Plano Diretor. Belém: Diário Oficial do Município.

Belém. (2007). Documento Base da Revisão do Plano Diretor de Belém. Belém: Prefeitura Municipal de Belém.

Belém. Prefeitura. (2019). Belém. Recuperado em 8 de julho de 2019, de http://www.belem.pa.gov.br

Brasil. (1998). Constituição de 1988. Brasília: Editora do Senado Federal.

Companhia de Desenvolvimento da Área Metropolitana de Belém - CODEM. (1970). Lei de criação. Belém: Diário Oficial do Município.

Companhia de Desenvolvimento da Área Metropolitana de Belém - CODEM. (1975). Subsídios e diretrizes para a montagem dos sistemas administrativos e de planejamento da Área Metropolitana e do município de Belém. Belém.

Companhia de Desenvolvimento da Área Metropolitana de Belém - CODEM. (1978). Análise das funções metropolitanas. Belém.

Companhia de Desenvolvimento da Área Metropolitana de Belém - CODEM. (2005). Belém.

Deák, C. (2004). 0 processo de urbanização no Brasil: falas e façanhas. In C. Deák, \& S. R. Schiffer (Eds.), O processo de urbanização no Brasil. São Paulo: EDUSP.

Fernandes, D., Jr. (2001). 0 sistema gestor da Região Metropolitana de Belém. Metrópolis em Revista, 3, 21-28.

Ferreira, M. (2007). Planejamento urbano nos tempos do SERFHAU: o processo de construção e implementação do Plano Diretor de Desenvolvimento Integrado de Franca (Tese de doutorado). Escola de Engenharia de São Carlos, Universidade de São Paulo, São Carlos.

Instituto Brasileiro de Geografia e Estatística - IBGE. (2013). Censos demográficos (pp. 1872-2010). Brasília: IBGE.

Lamarão Corrêa, A. J. (1989). O Espaço das ilusões: planos compreensivos e planejamento urbano na região metropolitana de Belém (Dissertação de mestrado). Programa de Pós-graduação em Planejamento do Desenvolvimento Regional, Núcleo de Altos Estudos Amazônicos, Belém.

Lefebvre, H. (2001). $O$ direito à cidade. São Paulo: Moraes.

Lopes, A. (2006). Gestão metropolitana no Brasil: da coerção simétrica ao voluntarismo sem com resultados. In C. A. Silva, D. G. Freire, \& F. J. G. Oliveira (Eds.), Metrópoles: governo, sociedade e território. Rio de Janeiro: DP\&A; FAPERJ.

Moreira, A. C. M. L. (1989). O novo e o velho plano diretor (pp. 186-191). São Paulo: FAUUSP.

Pacheco, R. S. (1995). Gestão metropolitana no Brasil: arranjos institucionais em debate. In L. Valladares, \& M. P. Coelho (Eds.), Governabilidade e pobreza no Brasil. Rio de Janeiro: Civilização Brasileira. 
Pará. (1980). Estudo de transportes urbanos da Região Metropolitana de Belém. Brasília: Empresa Brasileira de Planejamento de Transportes. Estudo de Transportes Coletivos.

Pinheiro, A. C. L., Rodrigues, R. M., Ponte, J. P. X., Monte, L. F. O., \& Sabino, T. A. G. (2013). Desafios da governança metropolitana na Região Metropolitana de Belém: alguns apontamentos. In M. A. Costa, \& I. T. L. Tsukumo (Eds.), 40 anos de Região Metropolitana no Brasil (pp. 47-67). Brasil: IPEA.

Rodrigues, E. B., \& Novaes, J. S. (Eds.). (2002). Luzes na floresta: o governo democrático e popular em Belém (19972001). Belém: Prefeitura Municipal.

Santos, S. S. (2015). Entre transformações e permanências: os institutos de planejamento urbano de Florianópolis e Joinville (Tese de doutorado). Programa de Pós-graduação em Geografia, Universidade Federal de Santa Catarina, Florianópolis.

Santos, T. V. (2010). Fronteiras de papel: uma análise da perspectiva metropolitana em planos diretores da Região Metropolitana de Belém (Dissertação de mestrado). Universidade Federal do Pará, Belém.

Souza, M. L. (2010). Mudar a cidade: uma introdução crítica ao planejamento e a gestão urbanos. Rio de Janeiro: Bertrand Brasil.

Trindade, S. C. C., Jr. (1998). A cidade dispersa: os novos espaços de assentamentos em Belém e a reestruturação metropolitana (Tese de doutorado). Faculdade de Filosofia, Letras e Ciências Humanas, Universidade de São Paulo, São Paulo.

Editor: Fábio Duarte

Recebido: Jul. 08, 2019

Aprovado: Dez. 25, 2019 